\title{
Miranda
}

Revue pluridisciplinaire du monde anglophone /

Multidisciplinary peer-reviewed journal on the English-

speaking world

$18 \mid 2019$

Guerre en poésie, poésie en guerre

George S. Schuyler, Black No More. Ou le récit d'étranges et merveilleux travaux scientifiques au pays de la liberté entre 1933 et 1940 après J.-C

\section{Christine Dualé}

\section{OpenEdition}

Journals

\section{Édition électronique}

URL : http://journals.openedition.org/miranda/17496

DOI : 10.4000/miranda.17496

ISSN : 2108-6559

\section{Éditeur}

Université Toulouse - Jean Jaurès

\section{Référence électronique}

Christine Dualé, « George S. Schuyler, Black No More. Ou le récit d'étranges et merveilleux travaux scientifiques au pays de la liberté entre 1933 et 1940 après J.-C », Miranda [En ligne], 18 | 2019, mis en ligne le 16 avril 2019, consulté le 16 février 2021. URL : http://journals.openedition.org/miranda/17496 ; DOI : https://doi.org/10.4000/miranda.17496

Ce document a été généré automatiquement le 16 février 2021.

\section{cc) (1)}

Miranda is licensed under a Creative Commons Attribution-NonCommercial-NoDerivatives 4.0

International License. 


\section{George S. Schuyler, Black No More. Ou le récit d'étranges et merveilleux travaux scientifiques au pays de la liberté entre 1933 et 1940 après J.-C}

Christine Dualé

\section{RÉFÉRENCE}

George S. Schuyler, Black No More. Ou le récit d'étranges et merveilleux travaux scientifiques au pays de la liberté entre 1933 et 1940 après J.-C. Introduction d'Ishmael Reed. Traduit de l'anglais (États-Unis) par Thierry Beauchamp. (Paris, Wombat, 2016) 251 p, ISBN :

978-2-919186-95-2, $20 €$.

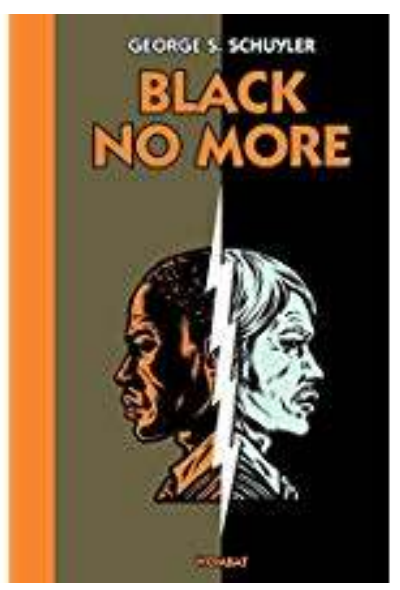

Que se passerait-il si l'Amérique réglait son problème racial en donnant la possibilité aux Noirs de devenir blancs grâce à un procédé médical ? C'est ce que le bien nommé docteur Junius Crookman, un escroc de génie, propose à la communauté noire de 
Harlem au début des années 1930 grâce à un mystérieux procédé de son invention. Max Disher se porte immédiatement volontaire et laisse « sa vie de nègre derrière lui » (42) car sa peau est devenue «couleur de porc» (42). Aux termes d'aventures rocambolesques, liées aux préjugés raciaux encouragés par une société qui a su établir « la frontière raciale » (59), Max Disher arrive à tirer avantage de sa nouvelle situation et sa nouvelle vie est prétexte à proposer une satire de la Renaissance de Harlem alors que les intellectuels noirs se préoccupaient de construire la culture noire américaine et appelaient à la fierté raciale.

2 George Schuyler est davantage connu pour ses chroniques dans les grands journaux noirs de la première moitié du vingtième siècle (Messenger, The Pittsburgh Courier, The Nation) que pour ce roman ignoré et oublié. Issu d'un milieu modeste, sa carrière de journaliste débute à New York dans les années 1920. Ses enquêtes dans les États du Sud des États-Unis, afin d'évaluer les relations et inégalités raciales, l'amènent à envisager un système de coopération entre travailleurs blancs et noirs pour le bien économique de tous. Il développe cette «théorie » dans Black No More (1931) à travers son personnage (devenu blanc) dont les escroqueries permettent la relance économique du pays. Cette satire mordante, qui lui valut les foudres de l'intelligentsia noire, était malheureusement tombée dans l'oubli. Redécouverte dans les années 1990 aux États-Unis, et rééditée plusieurs fois depuis, les éditions Wombat proposent une belle version française de Black No More. Traduite avec rigueur par Thierry Beauchamp, le roman ressuscite la période des années 1930 à Harlem, l'atmosphère de ses cabarets et le contexte racial sur fond de crise économique et de science-fiction.

3 Dès la dédicace, le message de George Schuyler se veut provocateur puisque le roman commence sur ces mots: "Ce livre est dédié à tous les Caucasiens de la grande République qui peuvent faire remonter leurs origines jusqu'à la dixième génération et affirmer sans ciller que leur arbre généalogique n'a pas la moindre branche, brindille ou feuille noires » (15). La question du métissage, encore très tabou dans les années 1930, est abordée dès les premières pages à travers un lexique riche et tout en nuance dont la traduction très fine permet d'évaluer le grand talent d'observateur, doublé d'une grande subtilité, de George Schuyler. Toutes les nuances de couleur de peau et les métissages possibles sont décrits par Schuyler et témoignent de ses qualités littéraires et de sa grande maîtrise du lexique qui est fort bien rendu en français. La palette des couleurs est riche et précise : "sa peau était marron clair » (21); « sa belle négresse dorée » (21) ; « ma damnée jaunasse » (22). Mais Max Disher et son acolyte, Bunny Brown, préfèrent « les filles café au lait » (23) aux vraies «négresses » ou aux femmes couleur «charbon » (23). George Schuyler propose donc une solution au «sujet le plus épineux de la société américaine. [...] S’il n'y avait plus de Noirs, il n'y aurait plus de problème noir » $(63)$.

Black No More raconte les aventures de Max Disher qui rêve d'une vie sans obstacles et de laisser « derrière [lui] les insultes, l'ostracisme, la ségrégation et la discrimination » (67). Hypnotisé par une superbe blonde rencontrée dans un bar de Harlem et qui lui refuse une danse puisqu'elle «ne danse jamais avec les nègres » (28), il se prend à rêver d'un monde inverse, l'antithèse de ce qu'il connaît depuis toujours: "il rêva qu'il dansait avec elle, dînait avec elle, roulait en voiture avec elle, siégeait à côté d'elle sur un trône en or pendant que des millions d'esclaves blancs entravés se prosterneraient devant lui » (29). Après l'intervention du Dr Crookman, Max Disher devient le blanc Matthew Fisher et voit son rêve prémonitoire se réaliser. Cependant, cette 
transformation est avant tout le résultat d'une manœuvre opportuniste où l'idéologie raciale semble avoir peu d'importance: «Il aurait besoin d'argent pour pouvoir jouir pleinement de sa condition de Blanc; alors pourquoi ne pas tirer profit de son histoire? » (43).

5 Maniant l'ironie et le sarcasme avec habileté, les aventures du héros de George Schuyler ne sont pas sans rappeler celles d'un autre personnage, Jesse B. Simple, créé par Langston Hughes une décennie plus tard. Hughes avait déjà répondu à « The NegroArt Hokum », que Schuyler avait publié en 1926 dans "The Nation », avec son célèbre manifeste "The Negro Artist and The Racial Mountain». Schuyler avançait que les Noirs américains n'avaient pu créer une forme d'art qui traduise et reflète leur culture en raison de l'influence de la culture blanche: «there's no such thing as AfricanAmerican art because of the influence of white models and participations of Whites. African American art is just American art " ("The Negro-Art Hokum," George S. Schuyler, Nation 122 (June 16, 1926) : 662-3). Pour George Schuyler, Blancs et Noirs étaient exposés à la même culture et il n'existait pas un art noir américain, ce en quoi il s'opposait à Hughes qui lui répondit à travers son manifeste en exhortant les artistes et écrivains noirs à se débarrasser du complexe d'infériorité et à revendiquer leur fierté raciale : "J'ai honte pour le poète noir qui dit «je veux être un poète, pas un poète nègre ", comme si le monde de sa race n'était pas aussi intéressant qu'un autre monde" (Hughes, in Richet, ed, 1993, 131). Avec Jesse B. Simple, Langston Hughes réagit au héros de Schuyler mais en proposant un personnage qui convenait à la fois aux stéréotypes des Blancs et des Noirs. En réinvestissant les stéréotypes et en se les réappropriant, Hughes remit subtilement en cause le système dominant. Grâce à l'autodérision et au vocabulaire de son personnage il proposa des effets de drôlerie et de mise à distance tout en révélant une culture noire protéiforme, produit de la culture blanche mais aussi de l'expérience noire. Son succès fut immédiat alors que le portrait incisif de Max Disher/ Matthew Fisher et le point de vue beaucoup plus radical de George Schuyler ne lui offrirent pas la reconnaissance escomptée. Schuyler rejetait aussi la masse populaire, qu'elle soit blanche ou noire, pour son manque d'éducation et son provincialisme mais il n'hésita pas non plus à satiriser l'élite noire dans Black No More. Avec son héros, Schuyler dénonce l'endoctrinement idéologique et religieux dont étaient victimes le prolétariat blanc avec le Ku Klux Klan, et les Noirs avec la religion : « la similarité entre cette réunion et les orgies religieuses des Noirs les plus ignorants l'amusait. [...] Il se rendit vite compte qu'ils goberaient n'importe quoi s'il le braillait avec assez de force et de conviction » (88).

6 Les aventures cocasses du héros entrainnent le lecteur dans le Harlem des années 1930 et sont une mine d'informations sur la vie et les relations raciales de cette période. Harlem, «lieu de perdition » (28) où la bourgeoisie blanche vient s'encanailler à la tombée de la nuit dans ses clubs de jazz ségrégués et « se procurer des sensations fortes [...] en évitant les contacts » (28), ses logements aux loyers exorbitants où s'entassent la population noire arrivée massivement des États du Sud» (62), le succès du salon de défrisage de Sisseretta Blandish (69-71), copie de Madame C.J. Walker (première Africaine-Américaine devenue millionnaire grâce à ses produits pour défriser les cheveux), le dialecte noir ( « il n'y a pas de dialectes raciaux, seulement des dialectes régionaux » (37), les relations Blancs/ Noirs et le Ku Klux Klan, sont autant de sujets subtilement évoqués par George Schuyler dans ce roman. Maniant l'humour, la dérision et la satire à la perfection, Schuyler devient aussi historien en faisant allusion à la Grande Migration et à la transformation radicale du quartier de Harlem dans la 
première moitié du vingtième siècle. Harlem était effectivement une "Terre Promise " (99) pour les Noirs qui "arrivaient du Sud en troupeaux sans cesse plus nombreux " (99) pour fuir la violence et la ségrégation raciale; ce que confirme l'historien Ira Berlin dans The Making of African America. The Four Great Migrations (2010):

If greatness is measured by size, the Great Migration was great indeed. Between America's entry into the European war and the stock market crash in 1929, black men and women left the South at an average rate of 500 per day, or more than 15,000 per month. The evacuation of the black belt was particularly striking. [...] By 1930, more than 1.3 million resided outside the South, nearly triple the number at the turn of the century (Berlin 154).

7 De la description objective, voire historique, Schuyler passe à la satire en caricaturant allégrement l'élite de Harlem. C'est ainsi que nous retrouvons W.E.B. Du Bois sous les traits du Dr Shakespeare Agamemnon Beard, fondateur de la Ligue Nationale pour l'Équité Sociale, autrement dit la National Association for the Advancement of Colored People (NAACP), fondée par Du Bois en 1909; Alain Locke, qui en appelait à la fierté et l'intégrité raciales est devenu Dr Napoléon Wellington et Booker T. Washington, qui fit l'éloge de l'amélioration des conditions de vie des Noirs après l'esclavage, prôna la collaboration entre Blancs et Noirs en minimisant la ségrégation dans le Sud, est devenu le révérend Herbert Gronne qui «avait tour à tour été professeur d'université, travailleur social et ministre du culte, avait reçu l'approbation des Blancs et était ainsi doublement acceptable pour les Noirs. [...] Ses propos paraissaient radicaux aux Noirs mais se révélaient assez conservateurs pour satisfaire le conseil d'administration blanc de son établissement» (107). Marcus Garvey n'est autre que Santop Licorice, "fondateur et président de l'Association pour le retour en Afrique» (114) dont le message nationaliste et le programme racial séduisent de nombreux Noirs avant l'arrivée du docteur Crookman et de son procédé miracle. Tous les chefs de file, philanthropes, mécènes, sociologues et représentants de la Renaissance de Harlem sont brocardés avec une ironie mordante et caustique et font de cette histoire une fable satirique grinçante. Une galerie de personnages aux noms plus humoristiques et satiriques les uns que les autres ("Junius Crookman », "Révérend Ezekiel Whopper », "Walter Brybe », « Simeon Dump », « Samuel Buggerie », « Santop Licorice », pour n'en nommer que quelques-uns), et tous accompagnés d'une note explicative du traducteur, soulignent la grande maîtrise du langage de Schuyler et son esprit mordant. Les aventures de ces personnages témoignent aussi d'un écrivain visionnaire, très au fait des questions raciales, sociales et politiques de son époque. "Schuyler se frotte dangereusement à toutes sortes de problèmes dans son roman » (8) tout en disséquant brillamment le «Grand Mensonge américain » (8), c'est-à-dire la pureté raciale, que l'on soit d'origine européenne ou africaine. Pris au piège de leur obsession de pureté raciale, les Blancs apprennent avec stupéfaction leurs origines noires et voient leur rêve de suprématie blanche s'effondrer (209-214).

8 Toute l'ambiguïté de Schuyler réside dans son double discours mêlant à la fois fierté raciale et rejet de son appartenance, proposant une attitude extrémiste pour aussitôt la fustiger. Il exprime, en définitive, son insatisfaction que l'on soit d'un côté ou de l'autre de « la ligne de couleur» (the color line). Cette œuvre satirique, révèle aussi un auteur aux connaissances encyclopédiques et très en avance sur son temps puisqu'il évoque, bien avant la relecture des années 1990, l'héritage et le métissage multiculturels américains dans une langue très maîtrisée et impeccablement traduite. "Original et atypique, le roman de Schuyler nous offre un point de vue décapant sur l'hypocrisie, la 
démagogie et les magouilles populistes accompagnant l'obsession américaine pour la couleur de peau " (Reed, Préface). Ce roman montre aussi que les intellectuels de la Renaissance de Harlem ne parlèrent pas tous d'une seule et même voix et que ce mouvement fut loin d'être uniforme.

Comme le rappelle Ishamel Reed dans l'introduction au roman, «il n'y a rien de comparable » (11) à Black No More. Ce livre qui n'a pas eu la reconnaissance littéraire qu'il méritait, car il ne correspondait pas aux dictats de l'époque et la devançait, doit à présent être considéré pour ce qu'il est : « un classique américain » (11). La traduction très soignée et réussie de Thierry Beauchamp invite les lecteurs francophones à découvrir ou redécouvrir cette œuvre oubliée mais aussi le Harlem des années 1930 à travers un observateur à la marge intellectuelle mais un témoin subtil, intelligent et drôle de son époque.

\section{INDEX}

Mots-clés : antihéros, discrimination, fable, Harlem, humour, littérature afro-américaine, pamphlet, problème racial, relations Blancs/ Noirs, Renaissance de Harlem, satire

Keywords : African American literature, anti hero, discrimination, Harlem, Harlem Renaissance, humor, lampoon, racial problem, satire, Whites/ Blacks relations

\section{AUTEURS}

\section{CHRISTINE DUALÉ}

Maître de conférences HDR

Université Toulouse Capitole

christine.duale@ut-capitole.fr 